\title{
SUBSÍDIOS A REFORMULAÇÃO DA NORMA BRASILEIRA NB-140/65 - TIPIFICAÇÃO DE EDIFÍCIOS EM PORTO ALEGRE
}

\author{
ERCÍLIA HITOMI HIROTA ${ }^{a}$
}

\begin{abstract}
RESUMO
Este trabalho faz parte da dissertação de mestrado apresentada ao Curso de Pós-Graduação em Engenharia Civil da UFRGS e tem como objetivo subsidiar a sistematização da tipificação de projetos no âmbito do subsetor Edificações, visando, principalmente, a reformulação da norma brasileira NB-140, considerada no trabalho como base fundamental do processo de tipificação.

Constitui-se em um estudo exploratório das variáveis que definem a estrutura física das edificações, através de uma análise estatística de dados coletados em Porto Alegre.

$O$ trabalho conclui incentivando o desenvolvimento de pesquisas sobre o assunto, visando ao método desenvolvido para suprir a carência observada na área.
\end{abstract}

PALAVRAS-CHAVE: NB-140/65; Edificações; Tipificação de edifícios; Custos.

\section{1 - INTRODUÇÃo}

Este trabalho trata da caracterização do produto do subsetor industrial Edificações e da conseqüente identificação dos projetos padrão de uma determinada região.

O suporte técnico disponível atualmente nesta área é ainda bastante reduzido. Pode-se dizer que o primeiro instrumento técnico proveniente da preocupação com a caracterização de edificações surgiu em 1965, com a aprovação da norma brasileira NB 140 de Avaliação de Custos Unitários e Preparo de Orçamentos de Construção para Incorporação de Edifícios em Condomínio, no âmbito da Associação Brasileira de Normas Técnicas. Embora o tema seja abrangente, esta norma permanece, ainda hoje, como centralizador do conhecimento técnico no assunto.

O estudo realizado foi motivado pela instalação, na ABNT, de uma comissão de estudos para a reformulação da norma, tendo em vista uma série de falhas detectadas em sua aplicação na área de incorporação. Inicia-se, portanto, com uma revisão dos antecedentes da norma NB-140/65 e de seu campo de aplicações, no sentido de verificar, através de uma abordagem sistêmica, as origens das falhas apontadas pela comissão. Nesta revisão foi definida a questão da padronização de projetos como ponto fundamental, não somente do método adotado pela atual norma, mas também de toda e qualquer metodologia a ser proposta.

Neste sentido, o objetivo do trabalho é de buscar a definição de parâmetros para a identificação da tipicidade de edificações, atendendo à exigência de dinamismo imposta pelas alterações das características do produto decorrentes da mudança dos requisitos dos usuários e do avanço tecnológico da Construção.

Para tanto foi feito um estudo exploratório com a utilização de 30 projetos de edificações da cidade de Porto Alegre, cujas características básicas foram balizadas pelo cadastro da Prefeitura local. As informações colhidas destes projetos foram submetidas a uma análise estatística para verificação da consistência dos dados.

É importante salientar que o produto Edifício, além de não dispor de mecanismos expeditos e sistematizados de caracterização e qualificação, não é objeto de estudo de viabilidade e marketing como ocorre em outras indústrias, por falta de métodos sistematizados ou antes, de informações que subsidiem tais estudos. A análise desenvolvida neste trabalho dá margens ao desenvolvimento destes métodos, principalmente na área de viabilidade econômica de empreendimentos.

\section{2 - A NORMA NB-140/65}

A necessidade da regulamentação do setor de Incorporações Imobiliárias fez que fosse elaborada na ABNT, a Norma Brasileira NB-140 em 1965. Essa necessidade era decorrente das distorções observadas na comercialização

\footnotetext{
a Departamento de Construção Civil/CTU — Universidade Estadual de Londrina.
} 
de unidades autônomas em edifícios de habitação coletiva, tecnicamente denominadas Propriedades Horizontais.

Seu objetivo era estabelecer critérios para a caracterização dessas unidades, em termos quantitativos, qualitativos e, principalmente, de custos.

Devido à inexistência de mecanismos de atualização em seu conteúdo, a norma passou a apresentar uma série de falhas que prejudicaram o alcance de seus objetivos. Outro fator, talvez mais grave, que colaborou para o surgimento de tais falhas foi a inexistência de outros instrumentos técnicos na área de incorporação e de avaliação de imóveis (qualitativa e economicamente). Por isso, a norma vem sendo aplicada em segmentos da área de Edificações em substituição a esses instrumentos, provocando distorções óbvias. São discriminadas a seguir as principais falhas detectadas no estudo realizado:

- desatualização dos componentes de modelo de estimativa de custos;

- falta de sistematização para a tipificação de projetos;

- desconsideração da influência do padrão (baixo, normal ou alto) no tamanho das unidades autônomas e na proporção de áreas de uso comum com relação à de uso privativo;

- desconhecimento da origem dos métodos: escolha dos projetos, definição de padrões, pesos e componentes dos lotes básicos;

- omissão do conceito de fração ideal de terreno;

- imprecisão do memorial descritivo que define o padrão de acabamento;

- falta de critérios para determinação das áreas equivalentes de construção;

- falta de coordenação entre a norma e os códigos de obras e planos diretores, em termos de linguagem adotada;

$\mathrm{Na}$ análise realizada paralelamente aos trabalhos da comissão da ABNT, definiu-se como ponto central das falhas da NB-140/65 a adoção de projetos padrão que não atendem à representatividade da produção de edificações. Neste ponto, entende-se como fundamental a definição de objetivos e campo de aplicação da norma a ser reformulada para que as falhas apontadas possam ser efetivamente solucionadas.

No processo de reformulação da Norma, foram analisados seus preceitos no contexto atual e foram detectadas duas fontes básicas de distorções: o conceito de área equivalente de construção e a representatividade dos projetos padrão. A proposta da Comissão, até onde foi possível acompanhar, foi de eliminação dos projetos padrão através de elaboração de um sistema de ponderação de especificações de serviços ou módulos do edifício. A preocupação básica da comissão era de estabelecer uma sistemática justa de divisão de custos de contrução e de manutenção na Propriedade Horizontal.

Esta proposta evoluiu para a padronização de modulos de um edifício, originados do desmembramento de sua estrutura física segundo o acesso ao uso, criando-se projetos virtuais compostos de módulos padrão. Este processo, mesmo com a eliminação da escolha de um projeto padronizado no seu todo, ainda implica na definição de partes do edifício que apresentam características uniformes e representativas.

Conclui-se, portanto, que a questão da tipificação de projetos continua sendo o ponto central do método. Resta, então, definir os parâmetros que determinarão a representatividade, sem perder de vista os objetivos da Norma: caracterização quantitativa, qualitativa e custos.

\section{3 - PADRONIZA ÇÃO DE PROJETOS}

A padronização é um artifício adotado pela atual norma NB-140/65 para classificar as edificações, objetos de incorporação, visando a sistematização de sua aplicação. Este mesmo artifício é adotado pelos demais métodos de avaliação de custos unitários de construção e de cálculo de índices de acompanhamento da evolução destes custos. A necessidade da simplificação decorre da grande variedade de tipologias construtivas, bem como da gama de alternativas disponíveis, atualmente, em termos de especificações de materiais, o que conduz ao aparecimento de padrões diferentes de acabamento.

Ao mesmo tempo, o fato de um instrumento abrangente como é a Norma ser obrigada a adotar projetos padrão para ver viabilizada a publicação de parâmetros técnicos para a área de incorporação imobiliária não prejudica seus objetivos, na medida em que se buscam parâmetros de avaliação e não prescrições a serem atendidas.

Desta forma, entende-se que a busca desses parâmetros passa, necessariamente, pela seleção de projetos que sejam representativos de uma dada região. Além disso, esta representatividade deve ser analisada à luz de certos critérios, que atendam aos objetivos da norma. Ora, se objetivo da norma é o de estabelecer parâmetros para avaliação quantitativa, qualitativa e de custos dos empreendimentos, e se a padronização de projetos foi criada para uma avaliação de custos, que por sua vez gerou todo um mecanismo de avaliação quantitativa e qualitativa baseada também nos projetos padrão, então, a representantividade deve ser medida pelo custo e não pelas suas características geométricas.

\section{1 - Abordagem por elementos funcionais}

Considerando que a estrutura de custos deve nortear a seleção de projetos típicos de uma região, e considerando ainda, que esse reconhecimento deve ser feito de forma simplificada, passou-se a desenvolver o estudo da padronização através da análise dos custos dos elementos funcionais da edifificação.

Esta análise resulta da tentativa de sistematizar estudos já existentes sobre o assunto. Detectou-se, entretanto que, embora exista um número considerável de índices de acompanhamento de custos, são desconhecidos os métodos utilizados para a identificação de projetos padrão adotados. Além disso, a coleta de dados no subsetor Edificações deixa muito a desejar, na medida em que os órgãos responsáveis pelo controle de sua produção arquiva 
uma série de informações que inviabilizam o tratamento técnico e científico necessário para a identificação de projetos típicos com relação a sua estrutura de custos.

Diante da falta de subsídios para o desenvolvimento do estudo pretendido, optou-se pela obtenção destes elementos através de uma análise de projetos recentemente executados em Porto Alegre. A bibliografia consultada não se refere diretamente à determinação de projetos típicos, mas à modelagem do custo de edificações. Acredita-se que os parâmetros adotados devam refletir, de algum modo,' a estrutura de custo, tendo em vista o objetivo da Norma já salientado anteriormente.

Os parâmetros foram selecionados com base nos estudos desenvolvidos na área de modelagem do custo de edificações por elementos construtivos ou elementos funcionais. FERRY e BRANDON (1981) definem estes elementos como partes da edificação que desempenham sempre a mesma função, independente do tipo de construção ou de especificações. Apontam também algumas propriedades importantes:

a) qualquer que seja o elemento escolhido, sua definição deve ser precisa, no sentido de assegurar uniformidade de desmembramento, considerando-se os diferentes projetos e a possibilidade de existência de critérios diversificados;

b) o elemento deve ter uma participação significativa no custo da edificação;

c) o elemento dever ser facilmente identificado tanto no projeto como numa análise do orçamento.

$\mathrm{Na}$ revisão bibliográfica foram definidos os elementos funcionais de maior representatividade do custo de execução, desconsiderando aqueles relacionados com custos de operação e manutanção (FERRY \& BRANDON, 1981; MASCARO, 1985; ROSSO, 1980; SEELEY, 1976 e STONE, 1980):
a) paredes externas;
b) paredes internas;
c) circulação horizontal;
d) circulação vertical;
e) esquadrias;

Além destes, foram adotados no estudo desenvolvido, outros parâmetros físicos de caracterização do edifício como um todo:

f) área construída do pavimento tipo;

g) área construída do pavimento térreo;

h) área construída do pavimento de cobertura;

i) número de pavimentos;

j) índice de compacidade.

Este conjunto de variáveis subsidiam não só o estudo da representatívidade de projetos de edificações, mas também apontam para a possibilidade de desenvolvimento de análises de viabilidade econômica de empreendimentos.

\section{ESTUDO DE CASO EM PORTO ALEGRE}

A seleção de projetos de edificações utilizados neste estudo foi condicionada pelo instrumento disciplinador da ocupação do solo urbano, o Plano Diretor de Desenvolvimento Urbano (PDDU - Porto Alegre). Este instrumento induz, através dos índices de controle usuais - índice de aproveitamento e taxa de ocupação do terreno e altura - à construção de edificações preponderantemente baixas, de 2 a 4 pavimentos (TABELA 1). Tendo em vista a influência direta da legislação urbana na tipicidade das edificações, salienta-se que os resultados deste estudo referem-se especificamente à cidade de Porto Alegre. Entretanto, o objetivo final do trabalho é o delineamento de um método de classificação de projetos.

TABELA 1: Percentual de economias vistoriadas por ano e por altura de edificação, no município de Porto Alegre.

\begin{tabular}{c|c|c|c}
\hline ano & total de & 1 a 4 pav. & $\begin{array}{c}\text { mais de 4 } \\
\text { pav } \\
\text { (\%) }\end{array}$ \\
\hline 1971 & 4.177 & 61,96 & 38,04 \\
1972 & 4.643 & 77,70 & 22,30 \\
1973 & 4.059 & 60,97 & 39,03 \\
1974 & 3.386 & 63,94 & 36,06 \\
1975 & 4.725 & 45,12 & 54,88 \\
1976 & 5.903 & 53,28 & 46,72 \\
1977 & 5.446 & 43,58 & 56,48 \\
1978 & 10.146 & 65,87 & 34,13 \\
1979 & 13.709 & 60,00 & 40,00 \\
1980 & 14.532 & 61,17 & 38,83 \\
1981 & 16.409 & 52,37 & 47,63 \\
1982 & 20.645 & 54,68 & 45,32 \\
1983 & 15.286 & 69,48 & 30,52 \\
1984 & 7.514 & 61,23 & 38,77 \\
$1985^{*}$ & 2.963 & 55,28 & 44,72 \\
\hline
\end{tabular}

Fonte de dados brutos: Prefeitura Municipal de Porto Alegre (1986)

(*) 1 semestre de 1985 .

A determinação do tamanho da amostra não seguiu um rigorismo estatístico por motivo bastante simples: não foram encontrados subsídios em bibliografia nem em instituições ligadas ao ramo, para a determinação de um número representativo de projetos que atendesse aos objetivos do estudo. Em outras palavras, não há conhecimento da média nem do desvio padrão esperados para as variávies a serem estudadas. Optou-se, portanto, por analisar um mínimo de trinta projetos, o que possibilitaria desenvolver uma análise estatística preliminar.

Desta forma, foram analisados trinta projetos, escolhidos aleatoriamente e restritos por:

- altura em torno de 4 pavimentos;

- edificações residenciais;

- facilidade de acesso aos projetos arquitetônicos completos 
- obra concluída nos últimos 5 anos, em função da data a partir da qual passou a vigorar o atual Plano Diretor.

\section{1 - Variáveis analisadas}

Todas as informações utilizadas neste estudo foram extraídas exclusivamente dos projetos arquitetônicos, considerando-se que os projetos selecionados são uniformes, em termos de qualidade de acabamento.

As variáveis básicas deste estudo, discriminadas no item anterior, podem ser ainda classificadas em caracrísticas externas e internas.

\subsection{1 - Características externas:}

São consideradas características externas aquelas que definem o envelope de edificação. Incluem as limitações impostas pelos índices de controle urbanístico do PDDU, além das áreas de circulação térreas e, por analogia, a área construída do pavimento de cobertura:

A. área construída do pavimento tipo;

B. altura em número de pavimentos;

C.área de construção fechada no térreo;

D. área de contrução fechada da cobertura;

E. proporção de paredes externas por $\mathrm{m}^{2}$ de área construída do pavimento tipo;

F. proporção de abertura nas paredes externas;

G. índice de compacidade.

A. Área construída do pavimento tipo: define o tamanho da projeção horizontal que, ao lado da altura caracteriza o porte da edificação. É adotada neste estudo como parâmetro de outras variáveis:

percentual de circulação horizontal e vertical, área construída nos pavimentos térreo e de cobertura e coeficientes de paredes externas e internas. É importante salientar que as sacadas e terraços foram considerados elementos de fachada, neste estudo. Implica na exclusão dessas áreas da projeção do pavimento tipo, enquanto espaço ocupado e forma.

B. Altura: fixada estre 2 e 6 pavimentos, de acordo com o levantamento executado na Prefeitura Municipal.

C. Área de construção fechada no térreo: define a proporção de área de acesso à edificação. Poderia ter sido acrescida às áreas de circulação internas, mas considerando-se que existia uma forte influência do padrão de acabamento da edificação no tamanho e no uso das áreas térreas, além de haver diferenças significativas de custos entre as circulações nos pavimentos tipo e no térreo. Representada como um percentual da projeção do pavimento tipo.

D. Área de construção fechada na cobertura: assim como o térreo, o pavimento de cobertura pode ser conside- rado um anexo ao corpo da edificação. Tendo em vista a predominância de projetos com pavimentos de cobertura na amostra, optou-se por incluir também esta proporção de áreas como variável do estudo. Representada como um percentual da área do pavimento tipo.

E. Proporção de paredes externas: o objetivo desta variável é de relacionar os parâmetros verticais com um dado conhecido e facilmente determinável como é o caso da área do pavimento tipo. Num raciocínio simplista, implica na avaliação do grau de descontínuidade da envoltória da edificação. A bibliografia consultada aponta os paramentos verticais como elementos de grande relevância no estudo dos custos de edificações (MASCARO, 1985; SEELEY, 1976). É definida como metro linear de parede externa para cada $\mathrm{m}^{2}$ de área construída do pavimento tipo.

F. Proporção de aberturas nas paredes externas: define a proporção de áreas destinadas às esquadrias, elementos de grande participação percentual no custo da edificação: cerca de 6\% segundo MASCARO (1985). O parâmetro adotado neste caso não foi a área construída do pavimento tipo, tendo em vista o comprometimento das esquadrias na preponderância dos planos verticais sobre os horizontais.

G. índice de compacidade (Ic): esta variável mede a racionalidade de um projeto, a partir da relação de seu perímetro com o de um círculo. Esta comparação deriva de uma simples análise geométrica, onde se deduz ser o círculo a figura que comporta a maior área num menor perímetro. Extrapolando este raciocínio para o custo de edificações, significa dizer que quanto maior o Ic mais racional será o projeto. Definido pela relação perímetro do círculo/perímetro do projeto para uma mesma área inscrita.

\subsection{2 - Características internas:}

A distribuição dos espaços internos foi examinada segundo:

A. proporção de áreas de circulação no pavimento tipo; B. Proporção de paredes internas no pavimento tipo.

A. Proporção de áreas de circulação no pavimento tipo: as áreas de circulação foram analisadas segundo duas variáveis: uma englobando as circulações verticais e horizontais e outra considerando especificamente as horizontais. A análise destas áreas torna-se relevante na medida em que são ressaltadas por autores como MASCARO (1985), ROSSO (1980), SEELEY (1976) e STONE (1980). A justificativa para a distinção das duas variáveis é o fato de ter sido detectada uma uniformidade na área destinada à circulação vertical, ao contrário da horizontal, que está relacionada com a distribuição das unidades no pavimento e consequentemente com as dimensões deste. 
B. Proporção de paredes internas no pavimento tipo: analogamente às paredes externas considerou-se relevante analisar os projetos segundo os elementos verticais internos que representam também a distribuição dos espaços nos pavimentos. Definida como a relação metro linear de paredes internas/área construída do pavimento tipo.

Com relação ao tamanho das unidade autônomas, parece bastante lógico classificá-lo segundo o número de dormitórios. Na realidade, as tentativas de tipificação de projetos de edificação são unânimes em adotar este critério (ABNT, 1965; FORMOSO, 1986). O objetivo desta análise é, portanto, determinar o tamanho médio das unidades, de acordo com o número de dormitórios. A falta de subsídios para a avaliação qualitativa dos projetos, entretanto, não permite a verificação da influência deste fator no tamanho das unidades. Tomando como base o estudo realizado pela Secretaria de Planejamento de Porto Alegre (PORTO ALEGRE, 1977), pode-se concluir que o padrão de acabamento influencia diretamente esta variável (FIGURA 1).

FIGURA 1 - Área média de unidades habitacionais em função do número de dormitórios e padrão de acabamento.
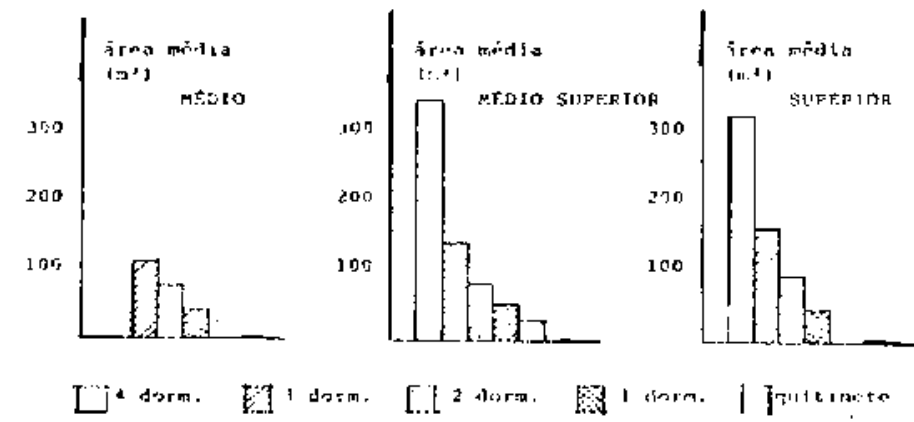

Cabe observar que o tamanho das unidades não faz parte da análise estatística, por não contar com número suficiente de informações (mínimo de 30) para um estudo de distribuição de dados (NANNI, 1981). Entretanto, partinda classificação generalizada em termos de número de dormitórios e assumindo a imprecisão devido à falta de elementos para a qualificação das unidades, foram determinadas as áreas privativas médias da amostra (TABELA 2), que apontam algumas tendências para esta variável.
A análise desta variável requer a determinação de parâmetros de qualificação, o que só pode ser feito com base em estudos do desempenho dos elementos funcionais, aliados a um modelo de estimativa de custo de execução. Torna-se, portanto, extremamente importante a elaboração de um instrumento técnico que padronize critérios para qualificação das edificações. Seria igualmente importante que este instrumento subsidiasse a NB-140 ou fosse parte dela.

\section{2 - Resultados obtidos}

As informações obtidas dos projetos analisados foram submetidas a uma avaliação estatística, cujo objetivo era de verificar a tendência da distribuição dos dados e não de determinar valores numéricos para as variáveis estudadas. O conhecimento do comportamento destas variáveis, sob o ponto de vista estatístico, torna-se importante na medida em que subsidia a modelagem de custos e principalmente, a sistematização da tipificação de projetos.

$\mathrm{Na}$ análise estatística desenvolvida foi utilizado o programa computacional STAT.BAS da UFRGS (NANNI, 1983), que tem por objetivo verificar a normalidade da distribuição de dados, através de testes de ajuste de curvas (Kolmogorov-Smirnov). Os resultados desta análise são apresentados na TABELA 3.

As variáveis, em gerai, apresentam distribuição simétrica e hipótese de normalidade não rejeitada, muito embora apresentassem coeficientes de variação acima do aceitável (com exceção dos coeficientes de paredes e do índice de compacidade). Segundo NANNI (1981) o valor de $25 \%$ seria razoável. Entretanto, considerando o caráter exploratório do estudo e o aspecto subjetivo da elaboração de projetos arquitetônicos, admite-se que:

- as variáveis obedecem distribuições normais;

- os coeficientes de variação refletem a heterogeneidade dos projetos a um nível aceitável.

Paralelamente, foi feito um estudo do tamanho de amostra necessária para aferir a curva de distribuição dos dados e os parâmetros encontrados. Admitindo-se um erro relativo de $10 \%$ e adotando a média e o desvio padrão das amostras como valores aproximados dos parâmetros do universo, obteve-se os valores apresentados na TABELA 4 .

TABELA 2 : área privativa das unidades em função do número de dormitórios

\begin{tabular}{c|c|c|c|c|c}
\hline $\begin{array}{c}\text { número de } \\
\text { dormitórios }\end{array}$ & $\begin{array}{c}\text { número de } \\
\text { observaç. }\end{array}$ & $\begin{array}{c}\text { menor valor } \\
\text { observado }\end{array}$ & $\begin{array}{c}\text { maior valor } \\
\text { observado }\end{array}$ & $\begin{array}{c}\text { média } \\
(\mathrm{m} 2)\end{array}$ & $\begin{array}{c}\text { coeficiente de } \\
\text { variação }\end{array}$ \\
\hline 1 & 16 & 30,31 & 54,51 & 38,75 & $17 \%$ \\
2 & 28 & 49,52 & 77,92 & 59,72 & $14 \%$ \\
3 & 13 & 65,45 & 171,60 & 93,25 & $29 \%$ \\
\hline
\end{tabular}


TABELA 3: Resultados da análise estatística das variáveis Programa STAT. BAS.

\begin{tabular}{|c|c|c|c|c|c|c|}
\hline $\begin{array}{l}\text { Funirofros } \\
\text { notatisticon } \\
\text { Vartavois }\end{array}$ & $\begin{array}{l}\text { cod:a } \\
\times \quad 111\end{array}$ & 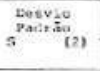 & 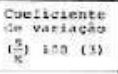 & 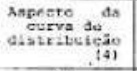 & $\begin{array}{l}\text { xoinoguzues } \\
\text { saintove (5) }\end{array}$ & 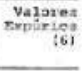 \\
\hline 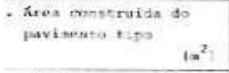 & $2 a v, 4$ & 122,8 & 331 & & 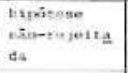 & - \\
\hline 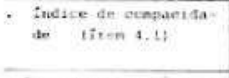 & 50.4 & 11,1 & 100 & & $\begin{array}{l}\text { hipócase } \\
\text { aisorejpita } \\
\text { da }\end{array}$ & - \\
\hline $\begin{array}{l}\text { - Areas techada so pavi- } \\
\text { senso testoo }\end{array}$ & 74,4 & 17,6 & 434 & & $\begin{array}{l}\text { Alposose } \\
\text { mat-regertas } \\
\text { in }\end{array}$ & $\begin{array}{l}100.0 \\
100,0 \\
151,2\end{array}$ \\
\hline 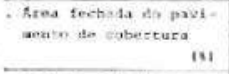 & 34.1 & 7,5 & 901 & & $\begin{array}{l}\text { bipózeas } \\
\text { päo-zejetia } \\
\text { da }\end{array}$ & - \\
\hline 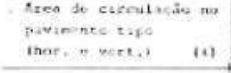 & 4.0 & 2,8 & 25. & & 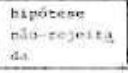 & - \\
\hline 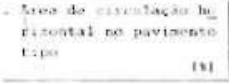 & 4,2 & 2.6 & 385 & & 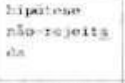 & $\begin{array}{l}12,5 \\
10,0\end{array}$ \\
\hline 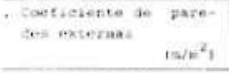 & 0.2 & 0.1 & 221 & & $\begin{array}{l}\text { Apoinse } \\
\text { ano-sejeits } \\
\text { ta }\end{array}$ & - \\
\hline 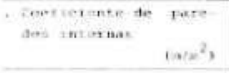 & 0,5 & 0,1 & 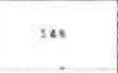 & & $\begin{array}{l}\text { nipitene } \\
\text { sion-rogeitat } \\
\text { an }\end{array}$ & - \\
\hline $\begin{array}{l}\text { Acertution na envelé } \\
\text { pare }\end{array}$ & 13.5 & 5,7 & $32 t$ & & $\begin{array}{l}\text { hipotese } \\
\text { nivorejeiter } \\
\text { da }\end{array}$ & - \\
\hline
\end{tabular}

Portanto, as médias encontradas para o índice de compacidade, área fechada do pavimento de cobertura, área de circulação horizontal e vertical no pavimento tipo e coeficientes de paredes externas e internas são aceitáveis, já que a amostra estudada tem um conjunto de dados maior que o necessário.

Por outro lado, a área construída do pavimento tipo e sua área de circulação horizontal apresentaram valores de $n$ duas vezes maior do que a amostra inicial. Este fato pode ser explicado pelas condicionantes provenientes do terreno, da legislação urbana, do padrão e da forma da edificação que levam a uma grande heterogeneidade de concepções arquitetônicas.

Por outro lado, os valores obtidos para o tamanho da amostra levam a crer que o desenvolvimento de estudos sobre a representatividade das edificações em uma dada região é limitada pelo número de projetos a serem analisados.

TABELA 4: Tamanho da amostra (n) para cada variável (erro relativo $10 \%$ )

\begin{tabular}{l|r} 
VA R A $\mathbf{A}$ E I S & $\mathbf{n}$ \\
\hline 1. área construida do pavimen to tipo & 59 \\
2. índice de compacidade & 7 \\
3. área fechada do pavimento térreo & 71
\end{tabular}

4. área fechada do pavimento de cobertura

5. área de circulação no pavimento tipo

6. área de circulação horizontal no pav. tipo

7. coeficiente de paredes externas

8. coeficientes de paredes intemas

9. abertura na envoltória

\section{CONSIDERAÇÕES FINAIS}

O trabalho aborda uma área ainda bastante árida para propiciar eficiência no seu desenvolvimento, mesmo tendo alcançado os objetivos traçados.

A análise da Norma NB-140/65 coloca a questão da representatividade dos projetos padrão adotados como ponto fundamental a ser estudado para a viabilização da reformulação pretendida pela ABNT. Neste sentido, o estudo desenvolvido em Porto Alegre propiciou o delíneamento de um método de avaliação desta representatividade, sem perder de vista os objetivos da NB-140, enquanto instrumento disciplinador da Incorporação de Imóveis.

Por outro lado, na análise estatística desenvolvida foi constatado que o número de projetos a ser analisado neste método proposto é viável para qualquer órgão responsável pela produção ou controle de custos de edicações.

Quanto a seleção das variáveis utilizadas neste estudo área de circulação no pavimento tipo, área do pavimento térreo, área do pavimento de cobertura, coeficientes de paredes externas e internas, percentual de aberturas na envoltória, índice de compacidade e área do pavimento tipo -, considera-se que, de acordo com a bibliografia, são as que melhor caracterizam a edificação segundo aspectos físicos e de custos. Além disso, sob o ponto de vista de concepção do projeto, as variáveis analisadas permitem uma relação direta com os índices de controle urbanístico ou parâmetros quantitativos do programa a ser atendido pelo projeto. Esta característica favorece o desenvolvimento de estudos de viabilidade econômica de empreendimentos área bastante carente de subsídios técnicos.

Finalmente, o desenvolvimento deste trabaho demonstra que a reformulação da norma brasileira NB-140/65 não é somente um processo rotineiro no âmbito da ABNT, mas uma importante oportunidade para reavaliar o conhecimento técnico na área de incorporação imobiliária e de acompanhamento do produto do subsetor industrial Edificações.

\section{ABSTRACT}

This paper takes of the dissertation presented to the Civil Engineering Post Graduation Course of UFRGS and its objective is to provide systematic standardization of typical building profects, specially in respect to the reformulation of the brasilian Code NB-140, considered here as the fundamental background.

It consists of an exploratory study of those variables, which define the physical structure of buildings through statistical analysis of data colected in Porto Alegre, in this area.

The data of this work suggested the necessity of developing the researches on this subject provide Information needed

KEY-WORDS: Code NB-140/65;Buildings; Building standardization; Building construction costs. 


\section{REFERÊNCIAS BIBLIOGRÁFICAS}

1 - ASSOCIAÇĀO BRASILEIRA DE NORMAS TÉCNICAS. A valiaçāo de custos unitários e preparo de orçamento de construçâoo para incorporação de edifícios em condomínio: NB-140/65. Rio de Janeiro, 1965.

2 - FERRY, D. J. \& BRANDON, P. S. Cost planning of buildings. 4 od. London, Granada, 1981.

3 - Formoso, C. T. Análise dos números indices da indústria da construçäo - subsetor edificações. Porto Alegre, CPGEC/UFRGS, 1986. cap. 4. p. 60-95. diss. mestr.

4 - HIROTA, E. H. Estudo exploratório sobre a titpificaçäo de projetos de edificaçōes, visando a reformulaçāo da norma brasileira NB-1 40/65. Porto Alegre, CPGEC/ UFRGS, 1987. diss. mestr.

5 - MASCARÓ, J. L. O custo das decisóes arquitetônicas. São Paulo, Nobel, 1985.

6 - NANNI, L. F. Análise estatística de dados com uso de técnicas computacionais. Porto Alegre, CPGEC/UFRGS, 1981. caderno téenico CT-30/81.
7 - NANNI, L. F. Programas computacionais para o processamento estatistico de dados. Porto Alogre, CPGEC/UFRGS, 1983. Caderno técnico CT-40/83.

8 - PORTO ALEgRE. Prefeitura Municipal. Secretaria do Planejamento Municipal - Área de habitaçăo. IN: --Relatorio do programa especial de reavaliaf̧āo do plano diretor. Porto Alegre, 1977. v. 7

9 - $-\ldots \ldots$. Prefeitura Municipal. Secretaria do Planejamento Municipal. Estatísticas. Porto Alegre, 1985.

10 - ROSSo, T. Racionalizaçāo da construção. São Paulo, FAU/USP, 1980 cap. 8 p.137-66.

11 - SEELEY, I. H. Bullding economics. 2 od. London, McMillan, 1976.

12 - STONE, P.A. Bulding design evaluation; costs-in-use. 3 ed. London, E \& FN Spon, 1980.

Recebido para publicação em 4/8/89 